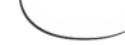

\title{
Diálogos (im)pertinentes de uma ética em pesquisa: apostas e conexões teóricas insurgentes em um saber implicado
}

\author{
Rogério Melo \\ Universidade Estadual Paulista \\ Bárbara Cossettin Costa Beber Brunini ${ }^{2}$ \\ Universidade Estadual de Maringá \\ Fernando Silva Teixeira-Filho 3 \\ Universidade Estadual Paulista \\ Murilo dos Santos Moscheta 4 \\ Universidade Estadual de Maringá
}

Resumo: Somos continuamente desafiadas/os a problematizar nossa recusa a inovar e enfrentar os lugares hegemônicos da produção de conhecimento. Porém, é preciso realizar este enfrentamento para reconhecermos o emaranhado de vozes e corpos que, de maneira coletiva e colaborativa, acionam outros gestos de implicações éticas/políticas/estéticas de se saber-fazer pesquisa. Assim, partindo das contribuições de teóricas/os feministas e queers, presentes em duas pesquisas de doutoramento, propomos conectar dois métodos: a cartografia e a pesquisa narrativa. Esperamos com isso, inspirar rupturas e subversões do status quo conceitual cisheteronormativo, eurocêntrico e colonial que, nem sempre, dão conta de nomear experiências vividas durante o processo de realização da pesquisa.

Palavras-chave: feminismos; queers; cartografia; pesquisa narrativa.

\footnotetext{
${ }^{1}$ Doutorando e bolsista CAPES em Psicologia na Universidade Estadual Paulista Júlio de Mesquita Filho/UNESP. Mestre em Psicologia e Sociedade pela Universidade Estadual Paulista Júlio de Mesquita-Filho/UNESP.

${ }^{2}$ Doutoranda em Psicologia na Universidade Estadual de Maringá. Mestre em Psicologia e Sociedade pela Universidade Estadual Júlio de Mesquita-Filho/UNESP.

3 Livre Docente em Psicologia e Docente do Curso de Pós-Graduação em Psicologia - UNESP/Assis-SP.

4 Doutor em Psicologia e Docente no Programa de Pós-Graduação da Universidade Estadual de Maringá/UEM.
} 


\title{
(Im) pertinent dialogues of an ethics in research: insurgent theoretical bets and connections in an embodied / a represented know-how
}

\begin{abstract}
Contemporaneity challenges us, continuously, to venture into the movements of problematization and friction of silences and refusals of other possibilities of production of knowledge that deflagrate the hegemonic places of production of knowledge, thus, recognizing the tangle of voices and bodies that collectively and collaboratively, trigger other gestures with ethical/political/aesthetic implications of knowing how to do research. Therefore, this essay intents in the dialogue /alliance between feminist theories and queer studies, both present in two doctoral researches, to venture into the theoretical-methodological connection of cartography with narrative research, to inspire clues and other proposals, of im/possible ruptures and subversions of the cis-heteronormative, Eurocentric and colonial status quo, in the face of the insurgent voices of the precarious and subordinate bodies of the present-future.
\end{abstract}

Keywords: feminisms; queers; cartography; narrative research.

\section{Diálogos (im) pertinentes de una ética en investigación: Apuestas teóricas insurgentes y conexiones en un saber hacer incorporado}

\begin{abstract}
Resumen: La contemporaneidad nos desafía, continuamente, a incursionar en los movimientos de problematización y fricción de silencios y rechazos de otras posibilidades de producción de conocimiento que desencadenan los lugares hegemónicos de producción de conocimiento, reconociendo así la maraña de voces y cuerpos que colectivamente y colaborativamente, desencadenan otros gestos con implicaciones éticas / políticas / estéticas de saber investigar. Asi que, este ensayo propone en el diálogo / alianza entre teorías feministas y estudios queer, presentes en dos investigaciones de doctorado, incursionar en la conexión teórico-metodológica de la cartografía con la investigación narrativa, inspirar pistas y otras propuestas, de caminos im/posibles de rupturas y subversiones del statu quo cisheteronormativo, eurocéntrico y colonial, frente a las voces insurgentes de los cuerpos precarios y subordinados del presente-futuro.
\end{abstract}

Palabras clave: feminismos; queers; cartografía; investigación narrativa. 
$\mathrm{E}$ ste artigo emerge das inquietações despertadas nos autores dessa produção no desenvolvimento de suas pesquisas de doutoramento, ambas em processo de execução, no campo dos estudos feministas e estudos queers, trajetórias que, aos poucos, estão sendo construídas no fazer em Psicologia e pensadas como ação política, compromisso ético e vivencial dos pesquisadores.

Uma delas está vinculada ao Programa de Pós-Graduação em Psicologia da Universidade Estadual de Maringá (UEM) no estado do Paraná, a nível de doutorado e tem como objetivo cartografar narrativas de mulheres docentes que se enunciam feministas e suas práticas descolonizadas na formação em Psicologia. A outra, vinculada ao Programa de Pós-Graduação em Psicologia da Universidade Estadual "Júlio de Mesquita Filho" (UNESP-Assis/SP), também a nível de doutorado, esta, se propõe a cartografar narrativas de homens-cis que se nomeiam e/ou se expressam a partir de corpos queers no cenário brasileiro.

As pesquisas se ancoram nas produções feministas e queers, e se constituem em um plano de experimentação no qual a e o pesquisador está implicada/o, bem como nos termos da relação de produção de conhecimento que se fazem ao longo do próprio processo de pesquisadores. Por isso, torna-se necessário criar formas de narrar e cartografar tais trajetos, seus movimentos e desenhos, suas materialidades e (des)conexões, uma vez que, o modo de propor uma pesquisa dessa natureza, não deve se confundir com a ilusão da aplicação de um método, mas, outrossim, deve permitir aos leitores a apreensão de uma construção situada, construída no entremeio da vida das/os colaboradores da pesquisa e dos próprios pesquisadores.

Desse modo, nos diálogos entre ambas as pesquisas, buscamos assumir o compromisso ético quando nos apresentamos como cartógrafos, na tentativa de não falarmos pelo outro, mas com o outro, colaboradores dessas pesquisas; um ato de reconto enquanto posicionamento político apresentado no trajeto repleto de possíveis desvios e sempre inacabado. Na cartografia, metodologia utilizada nas duas pesquisas, os olhares não são aqueles que se debruçam sobre o objeto para interpretar ou investigar, ele se constrói com e na pesquisa. Assim, participa da criação coletiva dos territórios por onde somos tensionados, sugerindo a invenção de novas expressões antes inexistentes no modo de estar e agir, transformando a paisagem subjetiva.

Torna-se ferramenta implicada em privilegiar vozes e experiências nãoautorizadas, as quais, por vezes, "hackeando os tímpanos da escuta científica para fazer passar, por eles, ruídos até então ignorados" (MOMBAÇA, 2016: 345), sendo fato que a produção de conhecimento não é e nunca foi desinteressada.

É nessa encruzilhada que nos colocamos e nos encontramos, forçando o pensamento a não generalizar e muito menos interpretar, buscando brechas para inventar estratégias que, minimamente, rompam com a lógica dominante da própria produção de conhecimento. Investimos em uma experimentação compatível com a problemática que nos mobiliza, concordando que o ato de cartografar pressupõe a escuta de certas narratividades, imersas em territórios onde a vida já está acontecendo, independente da produção científica, exigindo um processo de aprendizado do próprio cartógrafo e entendendo a pesquisa como 
um processo de criação coletiva.

Diante do exposto até aqui, ousamos ensaiar pistas de outras posturas éticas/políticas/estéticas; éticas por estarem socialmente comprometidas, traduzindo a implicação da pesquisa com os sujeitos que escolhem participar dela; políticas na medida que se engajam com as perspectivas de vidas dialogadas durante as pesquisas e expressam a responsividade dos pesquisadores perante o outro; e estética, ao contemplar as sensibilidades que estranham o instituído, as formas infinitas de estar, aquelas que reconhecem sua potência criativa.

A pesquisa cartográfica e narrativa não podem estar desarticuladas de tal postura, mesmo porque, se apresentam como decisão que nos implica enquanto pesquisadores. Tal implicação, nos posiciona ao lado das experiências vividas e evita os perigos do falar sobre, cultiva nosso posicionamento de estar com as vivências narradas e não sobre elas. São modos de fazer pesquisa que possibilita pensarmos outras formas de expressões de existência, para além das representações (ética); que implica-se com o compromisso da defesa de toda forma de vida, enquanto valor maior (política) e, que reconheçam a possibilidade de criação e instauração da alteridade nos/pelos transbordamentos da própria expressão agenciada nos acontecimentos e movimentos da/na experiência de ser vivente (estética).

O imbricamento entre os territórios de pesquisa, o procedimento, a posição política que assumimos enquanto psicólogas/os, agenciam nossa territorialização enquanto cartógrafas/os, que se afetam ao experimentar e fazer-se com estes encontros. Sueli Rolnik (2016: 2), caracteriza o cartógrafo como aquele:

\begin{abstract}
O que ele quer é participar, embarcar na constituição de territórios existenciais, constituição de realidade. Implicitamente, é óbvio que, pelo menos em seus momentos mais felizes, ele não teme o movimento. Deixa seu corpo vibrar todas as frequências possíveis e fica inventando posições a partir das quais essas vibrações encontrem sons, canais de passagem, carona para a existencialização. Ele aceita a vida e se entrega. De corpo e língua. Restaria saber quais são os procedimentos do cartógrafo. Ora, estes tampouco importam, pois ele sabe que deve "inventá-los" em função daquilo que pede o contexto em que se encontra. Por isso ele não segue nenhuma espécie de protocolo normalizado.
\end{abstract}

Neste processo de se avizinhar e habitar o campo, as pesquisas aqui apresentadas, estão se deparando com espaços de multiplicidades de lutas, militâncias, modos de estar no mundo, o que comprova a expressividade afetiva e afetantes das mesmas. Experiências performáticas em sua força de manter visível às realidades que compõem tais cenários e fazem emergir as linhas presentes nas narrativas dessas cartografias.

Assim, para a iminência do plano criativo de escrita destas pesquisas, foi necessário apresentar a dupla natureza da cartografia, pesquisa-intervenção, que indica esta metodologia como prática de construção de um plano coletivo de forças, geralmente ignorado por perspectivas tradicionais de conhecimento ainda dominantes, estruturadas por problemas, objetos ou sujeitos as quais desconsideram suas coexistências no plano de forças que os produzem, restrito aos contornos formais da sua construção.

A cartografia exige mais que uma atitude analítica ou descritiva, trata-se de mostrar que todo campo de pesquisa/observação emerge de nossa implicação com estes territórios e sujeitos, constituem um fazer recíproco, constituintes de um coletivo que inaugura outras formas de realidades. 


\section{Abandonando os manuais e apostando em outras companhias: interlocuções possíveis entre a cartografia e pesquisa narrativa}

Quando nossos corpos são tensionados para o exercício de outros possíveis, inclusive na pesquisa, nos vemos instigados a pensar em formatos de pesquisasinterventivas, ou seja, pesquisas que ultrapassam as instruções teóricas e transportam a vida às ações de militância, de reconhecimento de diferenças, por acreditar na potência de linhas de vizinhança enlaçadas à postura ética e política entre as teorias feministas e os estudos queers, uma vez que "a escolha de um método não é apenas uma questão epistemológica, mas também ética e política" (KASTRUP e PASSOS, 2013: 403).

Tal exercício, se fez presente em uma das pesquisas citadas nesse artigo, pesquisa essa que, ao acompanhar as experiências de homens-cis que se expressam e/ou se nomeiam enquanto corpos queers no cenário brasileiro, investiu nas contribuições que a interlocução entre a dimensão processual da cartografia e os Estudos e Perspectivas Queer propiciam para elaboração/acontecimento de "[...] novas linguagens em função daquilo que pede o contexto em que se encontra" (SILVA, 2018: 39), para assim, apresentar experiências de vidas nas suas intensidades e singularidades, indo contra lógicas interpretativas que favorecem, por vezes, que tais experimentações e vivências dissidentes ainda permaneçam como corpos não permitidos a ocupação de alguns espaços.

Com esse intuito e partindo da percepção de que os fenômenos/paisagens psicossociais se desenham em direções múltiplas e em constante movimento e mutação, correu-se os riscos de apostar no campo das sensibilidades agenciadas nos (des)encontros das vidas que se colocam sempre em processo e sintonia com o intempestivo, com as instabilidades, aberturas, acasos, incertezas, etc. E isso, sem dúvida, exigiu certa ampliação das estratégias de pesquisa, suscitando meios de ativar outras percepções para recepção do desconhecido, do que poderia se apresentar nos entre-lugares dos modos de subjetivação dos colaboradores protagonistas da referida pesquisa cartográfica. Pois, a cartografia possibilita acompanhar os processos em uma indissociabilidade entre a transformação e o conhecimento, tanto do pesquisador/analista, quanto das realidades, mediante uma perspectiva de pesquisa-intervenção que se faz sem distanciamento e que se encontra "[...] mergulhada na experiência coletiva em que tudo e todos são implicados" (PASSOS e BARROS, 2015: 19).

É a criação de outras estéticas de pesquisa, de "partilha do sensível" que vai se materializando em suas processualidades e movimentos, (re)construindo-se ao mesmo momento que vão acontecendo; por isso, não se pauta em relações de semelhanças e nem tampouco identitárias, muito menos tem a pretensão de desvelar o que já estaria posto como realidade preexistente.

Assim, ao acompanhar as experiências de homens-cis que se nomeiam e/ou se expressam enquanto corpos queers no contexto brasileiro, tal pesquisa ao reconhecer que o comum partilhado por eles se atenha ao termo queer e/ou os Estudos e Perspectivas Queer, as experiências vivenciadas por cada participante em relação ao queer e de como o queer atravessou e, ainda atravessa sua história de vida, singular, processual... acontecimento inédito, por isso, não pode/deve ser encapsulado em categorias e/ou em modelos prontos e interpretações generalistas. As experiências trazidas nas vozes contestatórias dos relatos dos participantes da referida pesquisa, provocaram o deslocamento do corpo de cartógrafa/o para instalar-se na dimensão do sensível, ou seja, no campo dos 
afetos e da sensibilidade, em tentativa de dar língua ao campo de afetações que pediam passagem no seu encontro com o inesperado e inédito que emergiram nesse aventurar-se que o campo propicia ao ser habitado e transitado enquanto processo.

Logo, analisando a dimensão processual da pesquisa cartográfica, Kastrup e Barros (2015) advertem sobre a necessidade de refletirmos sobre os sentidos do termo processo, isto é, lembrando o que este pode assumir quando remete à ideia de processamento. Ele evoca a concepção de conhecimento advindo da teoria da informação e praticada como coleta, análise de informações e regras de um certo método. Assim, ele se difere do termo processualidade, quando a pesquisa tem como objetivo a investigação de processos de subjetivação sempre em trânsito e incompletos.

De acordo com as teóricas, os processos da pesquisa geralmente já se encontram em curso, já possuem história anterior à chegada da/o pesquisador/a exigindo que os passos da pesquisa não sejam programados pelos problemas pensados, mas sim por movimentos constantes do próprio plano dos acontecimentos. Cada passo é sucedido pela processualidade dos dados produzidos (não coletados) durante a viagem da pesquisa-intervenção da/o cartógrafa/o, compartilhada com as pessoas que surgiram nos caminhos percorridos.

A cartografia prefere nomear estes territórios não de campos, mas de planos de pesquisa, o que desestabiliza a própria noção de campo modulado por seus limites e resistências. Acolhe o conceito de transversalidade proposto por Guattari (1964) para problematizar estes limites na defesa de processos que acontecem pelas frestas das formas, aqueles que impulsionam a criação e oportunizam a comunicação entre os participantes da pesquisa. Desta forma, acompanham o traçado dos encontros que ocorrem não apenas de modo vertical e horizontal, mas também transversal, dando consistência ao entre, a cartografia do intermediário, abandonando os manuais em suas fórmulas/forma/fôrma.

Assim, o imbricamento entre os territórios de pesquisa, o procedimento, a posição política que assumimos enquanto pesquisadoras (es) agenciam nossa territorialização enquanto cartógrafas/os, sujeitos que se afetam ao experimentar e fazer-se com/nestes encontros da ordem do acontecimento/afetação, efetivando sua cartografia enquanto estratégia de exercício sensível ao conceito de coletivo como plano efetivo da experiência do conhecer/fazer.

Doravante, a pesquisa cartográfica foi e é um experimentar, tanto no processo de pesquisar como no seu registro, pois os mesmos são agenciados por fluxos que "ora secam, ora congelam ou transbordam, ora se conjugam ou se afastam" (DELEUZE e PARNET, 1998: 60), que ao operar na tecedura dos acontecimentos, a cartografia não coleta dados a serem analisados - no sentido de interpretá-los - acompanha redes coletivas de sensibilidades, traços e/ou linhas que compõem esse mesmo plano na sua transversalidade e atualização (PASSOS e DO EIRADO, 2009).

Neste sentido, para a/o pesquisadora/o cartógrafa/o, não faz sentido seguir apenas trajetos dados previamente pela ciência, ou apenas coletar histórias. Fazemo-nos personagens destas contações de histórias vividas e visíveis (nem sempre) e compartilhamos os espaços que podem ser habitados por todas/os participantes, apresentando a pesquisa sempre como inacabada, o que possibilita sentidos alternativos para sua escrita por meio da ativação e ressignificação de nossas múltiplas experiências.

Nessa ótica, servimo-nos do recurso de relatos de histórias de vidas produzidas pelo manejo cartográfico de entrevistas, que se tornaram ao longo do pro- 
cesso, ferramentas/meios de acompanhar as marcas das experiências cotidianas de corpos de homens-cis que se percebem e/ou se nomeiam enquanto queers. Entrevistas estas que possibilitaram colocar em discussão às formas como o outro é constituído e percebido, onde a "diferença deixaria de estar ausente para estar presente: fazendo sentido, assombrando e desestabilizando o sujeito" (LOURO, 2001: 550); de maneira a friccionar os silenciamentos e recusas de outras possibilidades de produção de saberes que deflagram os lugares hegemônicos cisheteronormativos da produção de conhecimento, reconhecendo assim, o emaranhado de corpos e vozes que de maneira colaborativa e coletiva, acionam e provocam implicações éticas/políticas/estéticas de se saber-fazer pesquisa.

Assim, o que é possível à cartografia é acompanhar e problematizar os efeitos dos dispositivos e seus processos e modos de produção de subjetividades, o cruzamento e o embaralhar de suas linhas de subjetivação para a construção de um plano coletivo de forças. É vislumbrar, é experimentar locais que abrem mundos onde o desejo e a potência podem circular, que aumentam a possibilidade de bons encontros e impeçam a esterilização de modos de viver construídos por matrizes prescritivas e automatizadas que fazem a vida acontecer com potência diminuta (SPINOZA, 2009).

O mapa está aberto, ele "[...] adquire consistência suficiente para revirar uma situação" (GUATTARI apud DELEUZE, 1997: 76), gera redes afetivas de conexão no interrupto projeto de invenção de nós mesmos e extrapola a materialidade da ciência hegemônica. Tentando corroborar com saberes e diálogos que propõem outras maneiras de pensar o fazer pesquisa, seguimos na tentativa de construção de pontes, conexões e bricolagens necessárias.

\section{Narrativas: um convite às maneiras de misturar-se com alteridades e suas diferenciações}

A narrativa como método transporta a pesquisadora/o à descentramentos, retira o objetivo da linha reta e sugere a sensação do escapar por entre as regras o cronograma aparentemente estruturado, enriquece a experiência no mundo e aciona os fluxos de vida que ganham força nas audições perfiladas como um plano de imanência. A escolha pela metodologia cartográfica/narrativa, altera os mapas que orientam formas de vida e inventa imagens artísticas onde todo viver é pulsátil, performático e provisório, atravessa a materialidade finita dos corpos em relação para produzir conexões e experimentar encontros.

Por não estarem abertas à comprovação ou ao julgamento, tais narrativas são consideradas representações do mundo, expressam a verdade de quem conta, seu contexto e localização, vivencial, teórica e geográfica. Estas experimentações foram vivenciadas na produção da outra pesquisa citada por este artigo, interessada em escutar narrativas de mulheres docentes que se enunciam feministas em instituições universitárias privadas e públicas de diferentes estados brasileiros e suas práticas no ensino, pesquisa e extensão.

Nos encontros da pesquisa, as colaboradoras narram sobre como negociam seu estar docentes feministas, oferecem linhas, língua e ato as experiências vivenciadas no ensino, na pesquisa e extensão da formação em Psicologia. Mulheres interpretando suas vidas, utilizando-se de enorme potencial transformador para reinventar seus diferentes modos de estar no mundo, recriar-se mulher na e fora do espaço acadêmico. São corpos cênicos que amplificam sua voz e seu fazer, criando estratégias para tornar-se conectados entre si, desestabilizam, 
desterritorializam e vazam as molduras impostas às suas vidas, também na proposta de ações docentes feministas na formação em Psicologia.

A abundância de afetos que surgem durante a escuta das narrativas em uma pesquisa que se compromete a ouvir as experiências de mulheres docentes de Psicologia que se enunciam feministas, comprova nossa única certeza, escrever também é resistir. É desviar das pistas descritas em um projeto de pesquisa e hesitar diante as sequências de um grupo de objetivos pré-estipulados. A/o cartógrafa/o não só coleta histórias, é também personagem destas contações e disponibiliza espaços que podem ser preenchidos por todas colaboradoras/es, apresentando a pesquisa como inacabada, o que possibilita sentidos alternativos para sua escrita através da ativação e ressignificação de suas próprias experiências.

O processo de ir ao encontro dessas mulheres foi realizado, em um primeiro momento, buscando nomes de prováveis docentes de Psicologia que se enunciaram feministas nos nossos contatos profissionais e afetivos, também, em diversos eventos e sites onde estas mulheres assim se apresentam e através dos quais poderíamos anunciar a pesquisa e convidá-las a participar. Inicialmente, foi assim que aconteceu, mas a intimidade que emergia a cada telefonema, a cada recado deixado em e-mails, ou mensagens em outras redes sociais, aumentavam nosso desejo de procurar por todas e ampliava as paisagens que surgiam inéditas àquelas que nos eram tão familiares.

O projeto desta pesquisa foi entrevistar dez (10) psicólogas docentes de Psicologia de diferentes estados brasileiros e em suas múltiplas intersecções, profissionais implicadas com a pesquisa e escrita sobre feminismos, ou envolvidas em práticas de extensão, com no mínimo, cinco anos de experiência em docência do ensino superior privado ou público. Propomos à elas que as entrevistas não fossem realizadas necessariamente de forma presencial, mas organizadas de acordo com suas possibilidades, sendo sugerido o envio das narrativas por meio eletrônico caso não fossem possíveis as gravações em áudio/vídeo nos encontros presenciais devido ao período pandêmico da COVID19 que estamos atravessando.

Coube à escrita da tese, apresentar as narrativas das colaboradoras, mas também cabe ressaltar que, entre elas, estavam aquelas outras tantas que ampliaram nosso mapa e transbordaram os objetivos desta pesquisa. Ali estavam mulheres que, como descritas por Rago (2013), “[...] trilharam caminhos próprios, novos, dissidentes, dissonantes, abertos com trabalho árduo e com as sofisticadas ferramentas das desbravadoras" (RAGO, 2013. p. 34).

Vulneráveis a experimentação das histórias emergidas nos encontros com as colaboradoras, e no papel de pesquisador/a cartógrafa/o, transcrevemos, recontamos e sentimos cada narrativa, imaginando desenhos em suas linhas, anunciando o nosso corpo nos vestígios de suas falas e flertando com seu contar-se. Somos pesquisador/as-cartógrafas/os aprendizes, atentas/os, disponíveis à vivência que se faz além da experiência pessoal, da localização do corpo em territórios aparentemente parecidos com o da pesquisa por também estar docente feminista na formação em Psicologia.

A transversalidade da cartografia ampliou esta capacidade de comunicação entre colaboradoras e pesquisadora, favorecendo os acompanhamos e modulações dos territórios e os processos de subjetivação de cada colaboradora e suas realidades. Realidades observadas, por exemplo, quando apresentada na narrativa de uma colaboradora, a importância do momento o qual se entende feminista, e sobre o quanto tal percepção transforma seu estar e fazer no mundo, 
interferindo em suas relações pessoais e acadêmicas: "Hoje eu posso te dizer que nenhuma disciplina que eu lecione, mais de 50\% de qualquer disciplina que eu lecione, vai ter a presença de mulheres, intelectuais negras, qualquer disciplina que eu e lecione vai ter a presença de intelectuais fora do eixo hegemônico, qualquer disciplina hoje que o lecione, vou estar tencionando interseccionalidade, eu vou estar tencionando gênero, classe e raça e sexualidade entre outros marcadores sociais".

Assim, a escrita está sendo vivida no trajeto, reconhecendo o desejo de ser estendida, de ir além de um texto dissertativo, acadêmico, de espaços universitários, mas também, um texto afetivo, da ordem do pertencimento. Atitude que possibilita sentir as texturas da experimentação, e desliza o pensamento no âmbito das sensações, dos afetos, que "nos desestabiliza e nos coloca a exigência de criarmos um novo corpo, em uma existência, em nosso modo de sentir, de pensar, de agir, etc., que venha encarnar este estado inédito que se fez em nós" (ROLNIK, 1993: 2), indo além dos pontos de entrada que imaginamos para a pesquisa.

Acreditamos que a história relevante para a cartografia é aquela construída na narrativa de quem a faz e elenca os elementos que considera mais importantes, enfatizando os acontecimentos pertencentes e/ou pertinentes às suas vivências, aqueles que darão sentido ao seu presente. Atitudes ainda mais exigentes, quando falamos de profissionais que optam por uma prática reconstruída continuamente pelo fazer-se mulher em sua atuação profissional, política e feminista.

A narrativa como método visa o emergir de histórias entrecruzadas que encorajam a verbalização de acontecimentos sem interferência de quem pesquisa. O método propicia o aguçar da escuta para o espontâneo e para a criação de um texto colaborativo resultante destas trocas e interações implicadas com uma série de acontecimentos evocados no momento do encontro. Ela contribui para a elaboração de conhecimentos localizados e diálogos compartilhados, onde a sua construção se apresenta como elemento de investigação no campo psicossocial e possibilita "que algunas de las narrativas producidas em él sean re-analizadas o tomadas como punto de partida para estimulantes nuevos debates o trabajos" (BIGLIA e BONET-MATÍ, 2009: s/p).

Pensando na afirmativa de Clandinin e Connelly (2015: 48),

a vida - como ela é para nós e para os outros - é preenchida de fragmentos narrativos, decretados em momentos históricos de tempo e espaço, e refletidos e entendidos em termos de unidades narrativas e descontinuidades.

Por isso, consideramos que seria um erro tentar focar no entendimento ou interpretação da experiência do outro. É preciso escutar, permitir o envolvimento com suas narrativas e encontrá-las em suas vivências.

A pesquisa narrativa se compõe na intencionalidade de perceber as vidas experienciadas e contadas para além das estruturas quantificáveis, recortadas e fechadas. Isso porque, "o conhecimento que exprimimos acerca de nós mesmos e do mundo não é apenas um problema teórico, mas um problema político" (PASSOS e BARROS, 2015: 151). Defendemos, portanto, que a implicação ética da pesquisa narrativa, corrobora com a intencionalidade ética/política/estética de pesquisas que investem em uma produção de saberes encarnados, aqueles construídos para refletir o nosso posicionamento no mundo, implicados com os contextos da própria história, das memórias e experiências situadas, apresentados como objeto referencial em relação a localização cultural/histórica do/sobre o corpo.

Martinez-Guzmán e Montenegro (2014) compartilham da afirmativa de que 
o método narrativo propõe uma forma particular de ser, conhecer e fazer, articulando registros ontológicos, epistemológicos e metodológicos à abordagem de pesquisas qualitativas, aquelas como coprodução de narrativas em contextos de tensões, ocasionadas por regimes de verdade (FOUCAULT, 1990), como a que propomos ao buscar relato das colaboradoras/es de nossas pesquisas, descritos em seu tempo-espaço e que articulam ações de escape, éticas e políticas para as tramas presentes em nossas pesquisas.

Adotar o método narrativo é expandir as possibilidades de crítica à pesquisa e produções ocidentais que invisibilizam a diversidade de experiências e anulam os conhecimentos da/e pesquisadoras/es do sul global, recuperando o sentido de localização, de pertencimento, reconhecendo seu valor epistêmico anticolonial, verdadeiras ferramentas nas reivindicações de direitos sociais, denúncia de opressões e combate às violências, inclusive as epistêmicas. Neste sentido, em movimento de montagem e desmontagem, dos possíveis meios de fazer-se pesquisa unindo a cartografia à narrativa, encontramos caminhos que possibilitam acessar as múltiplas vozes contadas/narradas a partir do campo de afetações, experiências que provocam nossos corpos ética/política/esteticamente, fazendoos vibrar enquanto pesquisadoras/es, mas principalmente, enquanto seres viventes.

Tais ousadias são feitos fronteiriços, libertários dos moldes excludentes da tradição masculina amedrontada com o comportamento marginal que renuncia a produção de saberes advindos de vozes consideradas subalternas e que se encontram, inadvertidamente, em oposição ao idealismo tradicional, dando visibilidade às teorias e movimentos feministas e queers, potencialidades transgressoras de devires minoritários desterritorializadores dos regimes de poder/saber.

\section{Considerações [ainda] em experiências abertas e em movimentos}

A escrita deste artigo se apresenta como movimento intempestivo de um fazer-se pesquisa nas reinvenções da/na própria vida, tanto das/os pesquisadoras/es como das/os colaboradoras/es envolvidos nessa aventura do pesquisar, provocando tensionamentos na suposta primazia da "neutralidade" em pesquisa e fecunda de outras sensibilidades que possibilitam admirar os imprevistos e os diferentes fluxos que aconteceram em um espaço temporal aparentemente curto que estão sendo os quatro anos de vidas em doutoramento.

Histórias contadas nos encontros e entrevistas com cada colaborador(a) das pesquisas que estamos desenvolvendo, cartografias desenhadas por/nas experiências, narrativas e alianças entre as teorias feministas e estudos queers, que, ao comporem nossas pesquisas, instigam em nós, pesquisadoras/es e colaboradoras/es, outros movimentos e outros descentramento dos olhares, das escutas, das percepções e da própria escrita-pesquisa; tentativa provocativa de propor uma prática engajada e comprometida no ato de pesquisar, que busque viabilizar, eticamente, modos críticos, dialógicos e processuais na produção de um conhecimento situado e parcial (HARAWAY, 1995) na sua dimensão social, relacional, política e cultural.

Investimos assim, em uma perspectiva política que aciona nossas memórias, evocam as aprendizagens e as nossas utopias do/no mundo científico, aquelas que enveredam o corpo na construção de um saber interessado por histórias "vividas na carne", no trajeto de fazer-se, desfazer-se e refazer-se na produção de conhecimentos, distanciado de objetivos fechados a priori e por méto- 
dos/manuais que descrevem o caminho a ser seguido.

Nesta perspectiva, a cartografia e a pesquisa narrativa apostam na construção coletiva e no engajamento dos múltiplos corpos implicados/envolvidos no processo de pesquisa, gerando na/o pesquisador-cartógrafa/o, interesse, atenção e cuidado, pondo em constante análise suas convicções e conjecturas. Esta perspectiva, segue as marcas dos encontros e as produções de subjetividades, convoca não somente a participação de todas/os envolvidas/os mas também, garante seu protagonismo.

Ao apostarmos, na cartografia e na pesquisa narrativa para o desenvolvimento de nossas pesquisas, aceitamos correr o risco próprio desse processo, pois se trata de uma maneira ou de outra, de relatórios de pesquisas (teses). Reconhecemos os limites de negociação e renegociação com os lugares que nos encontramos vinculadas/os enquanto pesquisadoras/es. Sabemos que o nosso ponto de vista se faz mais profícuo e intenso quando nos mostramos indisciplinadas/os e desleais às suas normas convencionais.

Cabe dizer que, ao apostar na cartografia e na pesquisa narrativa como "ferramentas-processos-criações" de investigação, em consonância com os estudos que nos propusemos acompanhar, estudos feministas e estudos queers, criaram-se espaços de aparecimento que atribuem, significativamente, elementos para (re)pensarmos a importância das vozes e experiências não autorizadas e não legitimadas pelos estratagemas de saber/poder, encontrando e forjando, ao mesmo tempo, um conjunto de alianças e ligações que ousam contrabandear vitalidades, afetos e informações situadas nas paisagens psicossociais, seus modos de subjetivação e suas singularidades.

Recebido em 29 de janeiro de 2021.

Aprovado em 15 de maio de 2021.

\section{Referências}

BIGLIA, Barbara; BONET-MARTÍ, Jordi. "La construcción de narrativas como método de investigación psicosocial. Prácticas de escritura compartida”. Forum Qualitative Sozialforschung / Forum: Qualitative Social Research, 10(1). Disponível em: https://www.qualitative-research.net/index.php/fqs/article/view/ $\underline{1225}$

CLANDININ, D. Jean. CONELLY, F. Michael. Pesquisa narrativa: experiências e história na pesquisa qualitativa. Tradução: Grupo de Pesquisa Narrativa e Educação de Professores ILEEL/UFU. Uberlândia: EDUFU, 2015.

DELEUZE, Gilles. Crítica e clínica. São Paulo: Ed. 34, 1997.

DELEUZE, Gilles; PARNET, Claire. Diálogos. São Paulo: Escuta, 1998. 
de Philosophie, 84 (2) : 35-63, 1990.

GUATTARI, Felix. Psicanálise e transversalidade: ensaios de análise institucional. Aparecida: Ideias e Letras. 1964, 2004.

HARAWAY, Donna. Saberes Localizados: a questão da ciência para o feminismo e o privilégio da perspectiva parcial. Cadernos Pagu, 5: 7-41, 1995.

KASTRUP, Virginia; PASSOS Eduardo. Cartografar é traçar um plano comum. Editorial. Fractal, Revista de Psicologia. Niterói, 25 (2), 2013.

LOURO, Guacira Lopes. Teoria Queer - uma política pós-identitária para a Educação. Estudos Feministas, 9 (2): 541-553, 2001.

MARTÍNEZ-GUZMÁN; Antar, MONTENEGRO, Marisela. A produção de narrativas como ferramenta de pesquisa e ação sobre o dispositivo sexo / gênero: construindo novas histórias. Quaderns de Psicologia, 16 (1), 2014.

MOMBAÇA, Jota. Rastros de uma Submetodologia indisciplinada. Concinnitas, 17 (28), 2016.

PASSOS, Eduardo; BARROS, Regina Benevides. "Por uma política da narratividade”. In: PASSOS, Eduardo.; KASTRUP, Virginia.; ESCÓSSIA, Liliana. Pistas do método da cartografia: Pesquisa-intervenção e produção de subjetividades. Porto Alegre: Sulina, 2015. pp. 150-171.

PASSOS, Eduardo; DO EIRADO, André. "Cartografia como dissolução do ponto de vista do observador”. In: PASSOS, Eduardo.; KASTRUP, Virginia.; ESCÓSSIA, Liliana. Pistas do método da cartografia: Pesquisa-intervenção e produção de subjetividades. Porto Alegre: Sulina, 2009. pp. 109-130.

RAGO, Margareth. A aventura de contar-se: feminismos, escrita de si e invenções da subjetividade. Campinas: Editora da Unicamp, 2013.

ROLNIK Suely. Pensamento corpo e devir - uma perspectiva ético/ estético/ política no trabalho acadêmico. Cadernos de subjetividade, 2, 1993.

ROLNIK, Suely. Cartografia sentimental: transformações contemporâneas do desejo. São Paulo: Estação Liberdade, 2016.

SILVA, Mariah Rafaela Cordeiro Gonzaga da. Corpos Antropofágicos: Supermáquina e interseccionalidades em cartoescrita de fluxos indisciplinares. Dissertação de Mestrado, Ciências Humanas, Universidade Estado do Amazonas, 2018.

SPINOZA, Benedictus de. Ética. Belo Horizonte: Autêntica, 2009. 